\title{
Maud NAVARRE, Devenir élue. Genre et carrière politique
}

Rennes, Presses universitaires de Rennes, coll. « Res Publica », 2015, 257 p.

\section{Mathilde Dubesset}

\section{OpenEdition}

1 Journals

\section{Édition électronique}

URL : http://journals.openedition.org/clio/13127

DOI : 10.4000/clio. 13127

ISSN : 1777-5299

Éditeur

Belin

\section{Édition imprimée}

Date de publication : 1 juin 2016

Pagination : 305-307

ISBN : 978-2-7011-9852-1

ISSN : 1252-7017

\section{Référence électronique}

Mathilde Dubesset, «Maud navarre, Devenir élue. Genre et carrière politique », Clio. Femmes, Genre, Histoire [En ligne], 43 | 2016, mis en ligne le 23 août 2016, consulté le 23 septembre 2020. URL : http:// journals.openedition.org/clio/13127; DOI : https://doi.org/10.4000/clio.13127

Ce document a été généré automatiquement le 23 septembre 2020.

Tous droits réservés 


\title{
Maud NAVARRE, Devenir élue. Genre et carrière politique
}

Rennes, Presses universitaires de Rennes, coll. « Res Publica », 2015, 257

p.

\author{
Mathilde Dubesset
}

\section{RÉFÉRENCE}

Maud Navarre, Devenir élue. Genre et carrière politique, Rennes, Presses universitaires de Rennes, coll. « Res Publica », 2015, 257 p.

1 Ce livre, issu d'une thèse de doctorat soutenue en 2013 à l'Université de Bourgogne est une étude de la socialisation des femmes au rôle d'élue. L'auteure rappelle, dès l'introduction, la hiérarchie entre hommes et femmes dans le champ politique : dans la France de 2014, les femmes sont 15,9\% des maires, 5\% des présidents des Conseils généraux, et $7,7 \%$ des présidents des Conseils régionaux. Il s'agit donc de comprendre " les logiques sous-jacentes aux processus de différenciation selon le sexe, à l'œuvre dans la répartition des positions politiques, des attentes et de la prise de rôle ».

2 Le terme de «carrière » n'a pas la connotation négative du "carriérisme ». Il a ici le sens de parcours, de trajectoire, concepts mobilisés par la sociologie anglo-saxonne des années 1960, puis développés par la sociologie politique des années 2000. Il s'agit d'aborder la succession d'expériences des individus, les interactions entre engagement politique, sphère familiale et sphère professionnelle en tenant compte de la variété des situations. C'est la démarche adoptée par Maud Navarre dans cette étude qui intègre l'approche de genre et dont le terrain de recherche est la région Bourgogne où la féminisation des mandats politiques est proche des moyennes nationales. Les sources utilisées sont à la fois quantitatives (séries statistiques, questionnaires auprès des élu.es) et qualitatives (récits de vie recueillis durant l'année 2010, observations lors de la campagne des élections régionales de 2010 et d'assemblées au niveau local, départemental et régional en 2011). 
3 La campagne électorale constitue l'une des premières étapes de la socialisation au rôle d'élu. Les études réalisées au début des années 2000, lors de la mise en place de la parité pour certains scrutins, soulignent la valorisation des candidatures féminines incarnant le renouvellement du personnel politique. Mais l'objectif paritaire est rapidement rattrapé par le thème de "la diversité " et la scène électorale reste fermée aux candidates. Lors de la constitution des listes électorales, on constate une éviction des femmes des positions de leadership au profit d'hommes "professionnels » secondés par des femmes «novices ». Lors des réunions électorales, le monopole masculin des prises de parole est bien visible avec un usage fréquent du registre viril du combat guerrier et de la compétition sportive. Même si certaines listes (celles des écologistes par exemple) donnent plus de place aux femmes, celles-ci sont encore perçues comme des auxiliaires de la politique, dix ans après l'instauration des mesures paritaires.

4 L'élection acquise, les élues doivent trouver leur place dans des assemblées inégalement féminisées, certaines n'étant pas concernées par les lois dites "de parité " (Assemblée nationale et conseils généraux) à la différence des conseils régionaux et municipaux, assemblées plus récentes ou moins prestigieuses, où la féminisation est plus avancée. Pourtant, dans les conseils régionaux, vitrines de la parité à partir de 2010, la forte féminisation des vice-présidences n'a guère d'effet sur le partage entre domaines féminins (santé, affaires sociales, enseignement) et domaines masculins (développement économique, transports, finances, budget). Cette répartition sexuée des places pose la question des «capitaux militants et politiques » des femmes. Elles auraient un déficit dans ce domaine avec des engagements syndicaux, politiques et associatifs plus limités, mais elles peuvent mobiliser d'autres ressources, avec des niveaux d'études et de qualifications souvent supérieurs à ceux de leurs collègues masculins. Il faut donc interroger les effets de genre dans l'inégal accès aux responsabilités exécutives des hommes et des femmes.

5 Si le temps consacré à l'exercice du mandat montre peu d'écarts entre hommes et femmes, on note un investissement masculin plus marqué dans les activités de représentation (cérémonies, réunions publiques) tandis que les femmes s'impliquent plus dans la mise en place de projets. Or la construction d'une carrière politique doit beaucoup à ces moments de représentation, mais ceux-ci ne sont pas une priorité pour les élues qui y voient plutôt une perte de temps. Être élu requiert en effet une disponibilité qui oblige à réduire le temps consacré à l'activité professionnelle et aux tâches familiales, d'où la difficulté pour les élues «novices", plus jeunes, à concilier engagement politique, famille et profession tandis que les élues plus expérimentées, membres d'exécutifs, peuvent mobiliser davantage les aides extérieures. Mais les élues doivent aussi être capables de prendre la parole en public. Les observations de séances plénières d'assemblées montrent le caractère minoritaire des interventions féminines et le décalage, dans les types d'interventions, entre femmes et hommes. Ceux-ci s'expriment sur des questions générales tandis que les femmes interviennent sur des dossiers. L'aspect "mise en scène et jeux de rôles", fréquent dans ces séances plénières, est critiqué par les élues qui ont d'ailleurs des difficultés à obtenir et à garder la parole. Cette situation révèle un déficit de légitimité qui peut être intériorisé et exprimé par certaines élues. Mais d'autres réagissent à cette situation par divers moyens : l'arme de la séduction, non sans risques, l'intervention à tout prix, stratégie d'élues «semi-professionnelles», la critique des comportements masculins («ces élus qui font leur show») portée par des élues expérimentées qui veulent redéfinir les 
modalités de prises de parole, défendre la légitimité de femmes élues souvent confrontées au soupçon d'incompétence.

6 Tenir son rôle d'élue suppose des compétences - savoirs théoriques, savoir-faire pratiques et capacités relationnelles - acquises par les études, l'expérience professionnelle, l'engagement militant et «l'apprentissage sur le tas ». Très valorisé en politique, le leadership nécessite de savoir animer des réunions, diriger une équipe, entretenir des relations avec différents acteurs. Or la socialisation des femmes et leur moindre familiarité avec le milieu politique peut susciter chez elles un sentiment d'incompétence qui contraste avec la confiance dans leurs aptitudes affichée par les hommes. Ce décalage interroge la notion même de compétence et renvoie à la construction des rôles sexués. Des élues très diplômées notent, chez les acteurs politiques, la représentation courante de l'incompétence des femmes qui contribue au maintien du " plafond de verre " pour l'accès d'élues au leadership dans les assemblées.

7 La répartition sexuée du travail politique peut-elle être dépassée? L'étude des responsabilités détenues dans les assemblées montre que les femmes, même expérimentées, ne bénéficient pas des mêmes chances que les hommes d'accéder à toutes les responsabilités. Celles qui y parviennent disposent de "capitaux partisans » ou d'une notabilité dans leur territoire. Mais l'auteure pointe aussi la renégociation qui s'opère chez les élues entre une éthique politique altruiste connotée au féminin et la professionnalisation politique qui renvoie au masculin, tout en rappelant que «si la féminisation reconfigure la division sexuée du travail politique, elle n'y met pas fin ».

Le livre de Maud Navarre est dense, très documenté et d'une lecture agréable. Quelques interrogations : sur la grille de lecture du champ politique donnant parfois l'impression d'une réalité intangible ; sur une forme de neutralisation de la dimension critique des paroles de femmes qualifiées de "stratégies de compensation »; enfin sur la notion de « carrière de genre ».

\section{AUTEURS}

\section{MATHILDE DUBESSET}

ANHIMA (UMR 8210)

LARHRA 